\title{
Fuzzy logic aided PPF controller design to active vibration control of a flexible beam
}

\author{
Erdi Gülbahçe*1 (D), Mehmet Çelik² iD \\ ${ }^{1}$ KTO Karatay University, Mechatronics Engineering Department, Konya, Turkey \\ ${ }^{2}$ KTO Karatay University, Mechanical Engineering Department, Konya, Turkey
}

\begin{abstract}
This paper presents a fuzzy-logic-based observer and a positive position feedback controller to reduce a standard beam's free vibrations using a piezoelectric actuator. It is aimed that fuzzy-logic-based observer is used as feed-through and improves the overall performance of the PPF controller. For this aim, the cantilever beam and a piezoelectric patch are initially numerically modeled using the finite element method considering the close loop control algorithm. The displacement and strain responses results are compared with the experimental model. Then, two controllers are applied to the designed system: positive position feedback (PPF) and fuzzy-logic-based positive position feedback (FLBPPF). The uncontrolled and controlled system responses are investigated and compared in terms of the linear strain and tip displacement results. Using the FLBPPF controller, the settling times of controlled systems are decreased by about $20.7 \%$ and $41.6 \%$ regarding the linear strain and tip displacement response compared to the PPF controller.
\end{abstract}

\section{Keywords}

Active control; Flexible beam; Positive position feedback control; Fuzzy logic observer; Piezoelectric actuator

Received: 2 August 2021; Accepted: 21 August 2021

ISSN: 2630-5763 (online) C 2021 Golden Light Publishing All rights reserved.

\section{Introduction}

Active vibration control is studied to suppress or reduce redundant vibrations in structures using an actuator and sensor pairs. The harmful vibrations frequently occur in structures, and they need to be handled under control to prevent structural stability failure. Even when harmful vibrations do not exceed reasonable levels, transverse resonant vibrations can eventually cause the fatigue of structures and reduce the service life [1].

There are many other motivations for applying active vibration control to the structures. Most efforts on active vibration control are typically based on intelligent materials [2-4]. Smart materials such as piezoelectric, shape memory alloys, and magneto/electrorheological fluids have been used in various applications to implement the desired control strategies. Piezoelectric material-based actuators/sensors are widely used in vibration control studies. They provide comparable low-cost, large bandwidth, fast response, low-weight, reliability, and low power consumption properties actuating and sensing the vibrations in flexible structures [5].

There are several studies in the literature about piezoelectric material-based active vibration

\footnotetext{
Corresponding author

Email: erdi.gulbahce@karatay.edu.tr
} 
control with different goals. Zhang et al. [4] studied thin-walled structures to achieve vibration suppression with a controller design. They implemented a PID control to suppress both free and forced vibrations according to vibrations excited by various disturbances. Boz et al. [2] investigated a thin, flexible smart plate with an optimal velocity feedback controller using surfacebonded piezoelectric patches as actuators while using a collocated vibrometer as the velocity sensor. Similarly, Liu et al. [3] presented an optimum control method for a nonlinear vibration system that is a flexible, simply-simply supported beam with a piezoelectric sensor and actuator. They emphasized the delayed control in nonlinear systems has a significant role in vibration control engineering, and the study of delayed vibration control of nonlinear systems is essential. In literature, it is observed that there are two essential processes in active vibration control. The first process is the optimal placement of the sensor/actuator pairs, the most critical factor in determining controllability and observability. Researchers have made significant contributions to the literature about the optimal placement using different structures [6-8].

The second one is the effective controller design that is the primary purpose of this current study. The researchers developed control algorithms for active vibration control using plate-like flexible structures or flexible conical shells with piezoelectric actuators. Following this purpose, Lüleci [9] investigated active vibration control techniques with piezoelectric actuators, aimed to reduce vibrations of the first three bending modes of a cantilever beam with several modal control techniques such as resonant control (RC), integral resonant control (IRC), positive position feedback with feed-through (PPFFT) and positive position feedback (PPF). Wang et al. [10] introduced the adaptive robust sliding mode control algorithm based on Lyapunov's direct technique to reduce the beam's vibrations. They used the surface-bond PZT patches as a sensor and actuator for the active vibration control. Zhang et al. [11] investigated controller design problems of the robust finite frequency $\mathrm{H}_{\infty}$ passive fault-tolerant static-outputfeedback. Omidi et al. [1] also presented a technique for active vibration control in flexible structures. They developed the hybrid positive feedback (HPF) that uses two compensators. A second-order compensator for the displacement feedback and the first-order compensator for velocity feedback compose the controller. Parameswaran et al. [12] presented a robust controller based on the sliding mode method on a simple cantilever beam. They explained that the first two bending modes are controlled to investigate the improved control strategy's operational effectiveness. Nestorović and Oveisi [13] investigated the problem of a robust controller for the vibration reduction of an intelligent beam using a piezoelectric actuator to reach the desired robust stability. They proposed a multi-objective robust control strategy for vibration reduction of a smart cantilever beam. They have also worked on the development of classical controllers. The researchers have focused on improving the PPF controller design by developing several algorithms. Kwak and Heo [14] presented the multi-input and multi-output positive position feedback (PPF) controller for the grid structure to control vibrations. They reported that the MIMO PPF controller using the block-inverse method could reduce the proposed structure's lowest four modes with two sensors and two actuators. Orszulik and Shan [15] proposed a PPF controller using the adaptive online parameter estimator based on the recursive least squares method with a forgetting factor. Ferrari and Amabili [16] increased this controller's performance with the non-collocated configuration by using a PPF controller.

Beyond these studies, researchers presented active vibration control studies using fuzzy logic approaches. Zorić et al. [17] presented a particleswarm optimized self-tuning fuzzy logic controller for the active vibration control. They improved the FLC performance via a self-tuning process with membership function optimization using the PSO algorithm. Tairidis et al. [18] developed a genetic algorithm to optimize the fuzzy model's membership functions for active vibration control. 
The researchers have been worked on active vibration control in different studies [19-23].

This study uses a piezoelectric actuator and a strain gauge as the actuator/sensor pair for active vibration control. These are located in the root of the cantilevered flexible beam in a collocated controller design to decrease the structure's free vibrations. However, our previous study [24] included the numerically applied tuner-based PID and a positive position feedback controller for damping the structure's forced vibrations using a piezoelectric actuator. The numerical state-space model is also obtained similar to our previous study [24], using ANSYS/ Workbench software.

The paper's investigation introduces a fuzzylogic-based (FLB) observer to improve the positive position feedback (PPF) controller performance to damp the flexible aluminum smart beam's free vibrations. The fuzzy-logic-based observer is fed forward to the PPF controller in the control methodology for obtaining the proposed FLBPPF controller. The developed simulation model's strain and tip displacement responses are compared with the experimental setup results to verify the model. On the other hand, experimental studies are realized according to the modeling and controller design simulations. As a result of this study, uncontrolled system, PPF and FLBPPF controlled system responses can be investigated numerically and experimentally. Their performances are compared in terms of the strain and tip displacement results.

\section{Numerical modeling of smart beam and verification with experimental model}

A flexible aluminum beam is used as a prototype to show the proposed vibration control algorithms' efficiency. The dynamic characteristics of a structure are determined in order to tune control bandwidth for vibration suppression. A thin aluminum beam with dimensions $450 \times 35 \times 1.7 \mathrm{~mm}$ as the host structure and a piezoelectric patch with dimensions $50 \times 35 \times 0.7 \mathrm{~mm}$ as the actuator are used as parts of the smart beam. The piezoelectric patch is placed in the extreme strain region of the first four vibration modes. The aluminum beam and the piezoelectric patch are modeled in the ANSYS/Workbench software by considering the closed-loop cycle. The smart beam is shown in Fig. 1 as the numerical model and the experimental setup. The piezoelectric patch and the strain gauge are used as a pair of sensor/actuator, and they are placed on opposite sides of the aluminum beam at the exact corresponding location.

The numerical and the experimental modal analyses are implemented using the proposed models. The results of the modal analysis are presented in our previous study [24]. The experimental and numerical modal analysis results are close enough to each other. The "SPMWRITE" command $[9,24,25]$ used in calculating the statespace matrices provides a numerical model of the smart beam in ANSYS/Workbench. The numerical model's state-space matrices for the first four modes are calculated based on the modal parameters. The numerical model derived from the SPMWRITE command contains infinite or multiple modes information. Only the first four modes of the smart beam are used to avoid time-consuming analysis. Besides, the state-space model should include two inputs (the controller and the disturbance) and two outputs (the strain and the tip displacement).

The active vibration control experimental setup of the flexible smart beam is given in Fig. 2. The setup has two inputs (the controller and the disturbance) and two outputs (the strain and the tip displacement) to simulate the numerical model. A commercially piezoelectric patch (PI Dura-act 876.A12) is used as the controller actuator. A piezo amplifier for the piezoelectric patch (PI E-413.D2) amplifies the controller signal to levels between 250 and +400 Volts. A modal shaker is used as the disturbance actuator in order to stimulate the flexible smart beam. A strain gauge (120 ohms), by HBM, Inc., is used to measure the patch location's linear strain. An industrial laser displacement sensor (Micro-epsilon optoNCDT 1700) is used to measure the transverse displacement of the smart beam's free end. 


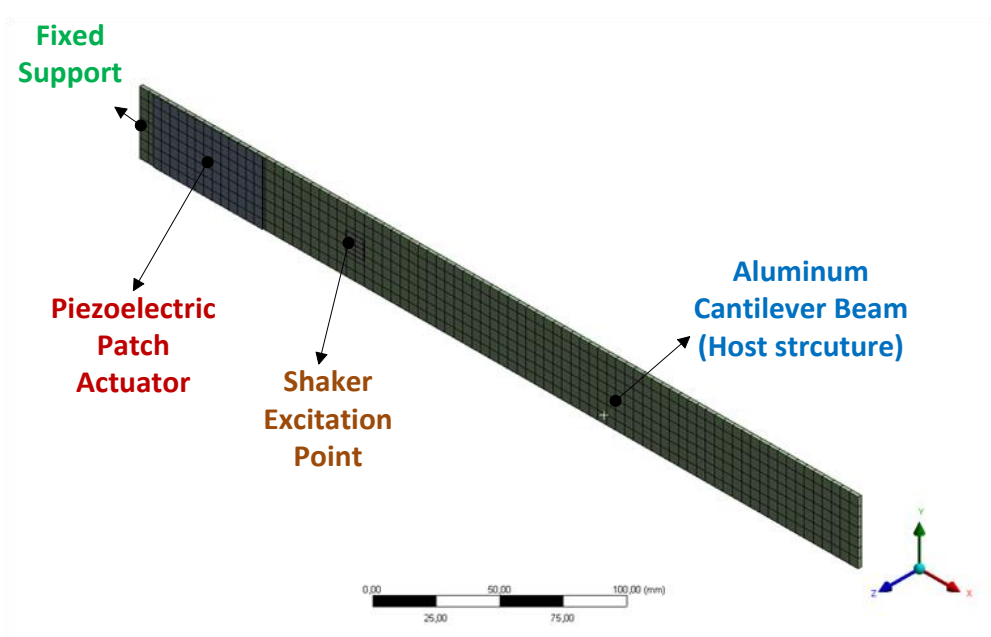

(a)

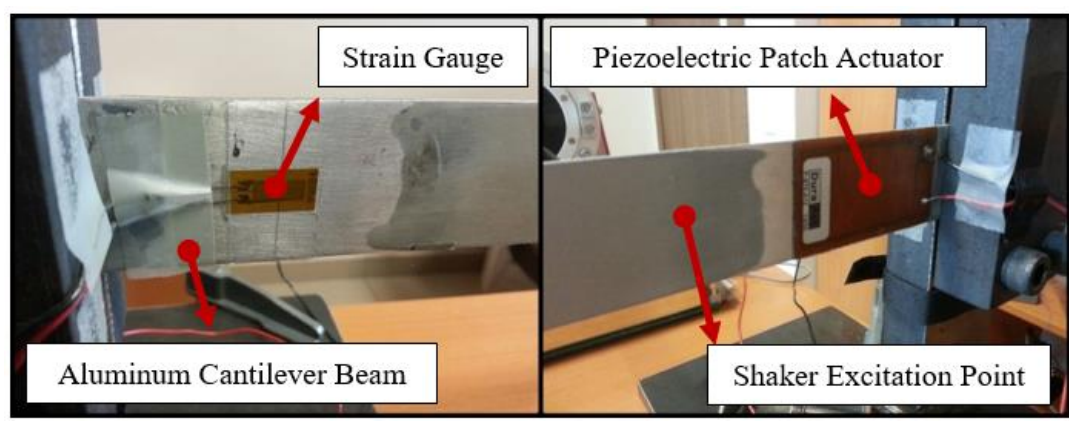

(b)

Fig. 1. (a) The numerical model, (b) The experimental setup

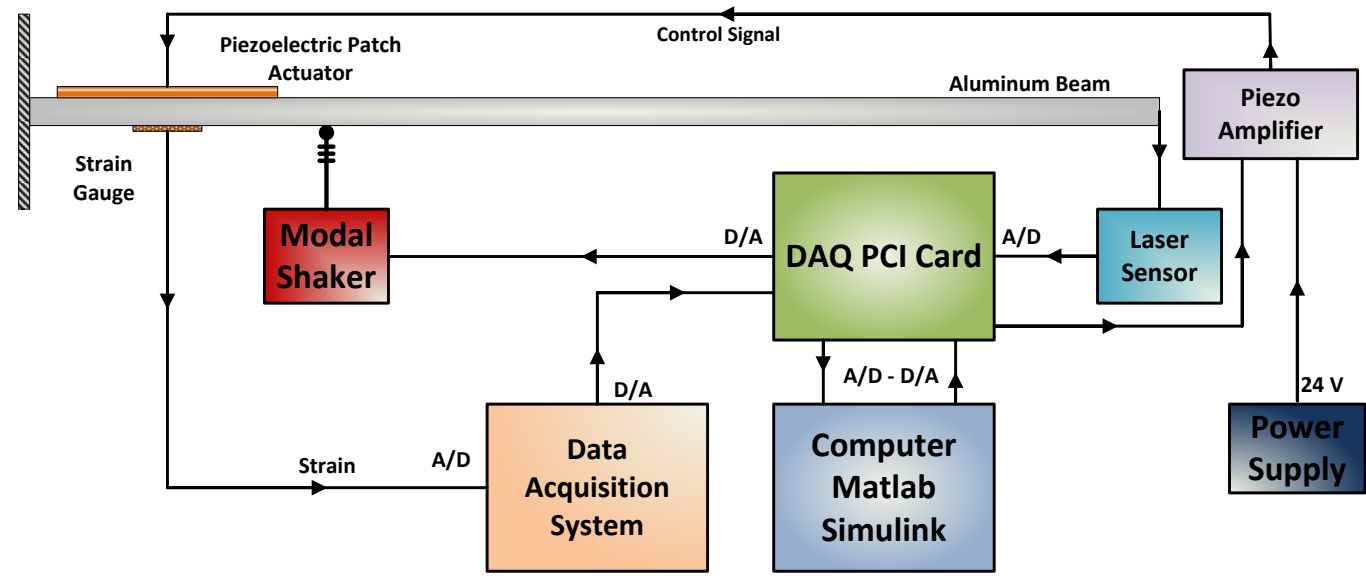

Fig. 2. The schematically experimental setup with a flexible smart beam

Finally, the data acquisition, controlling, and signal processing are operated by the data logger system (Dewesoft-Sirius) and the PCI I/O card (Humusoft-AD622) in MATLAB/Simulink/2015b. 
The numerical model is updated in order to correlate the dynamic characteristics of numerical and experimental models. Vibratory system responses are investigated in both frequency and time domains. The examination of the vibration systems in the frequency domain provides important information [1,16]. Similarly, timedomain investigations are also conducted in $[17,18]$. In numerical and experimental runs, the smart beam's strain and tip displacement responses are analyzed with two excitation inputs: the modal shaker and the piezoelectric actuator. The system is distorted with an excitation signal of $8 \mathrm{~Hz}$ near the first natural frequency to improve response verification clarity. The experimental model (Fig. 1.b) is driven by a piezoelectric patch sinusoidal signal with $8 \mathrm{~Hz}$ frequency and $\pm 50 \mathrm{~V}$ amplitude for 2 seconds. The linear strain and tip displacements are measured using the strain gauge and the laser displacement sensor. The laser displacement sensor is used only for response verification; it is not used in closed-loop control. Excitations are applied similarly to the numerical model. In Figs. 3 and 4, the comparisons of both responses piezoelectric patch excitation are given. It is seen that the linear strain and tip displacement responses RMS (Root Mean Square) values are matched at a rate of 94$97 \%$ for both numerical and experimental analysis results.

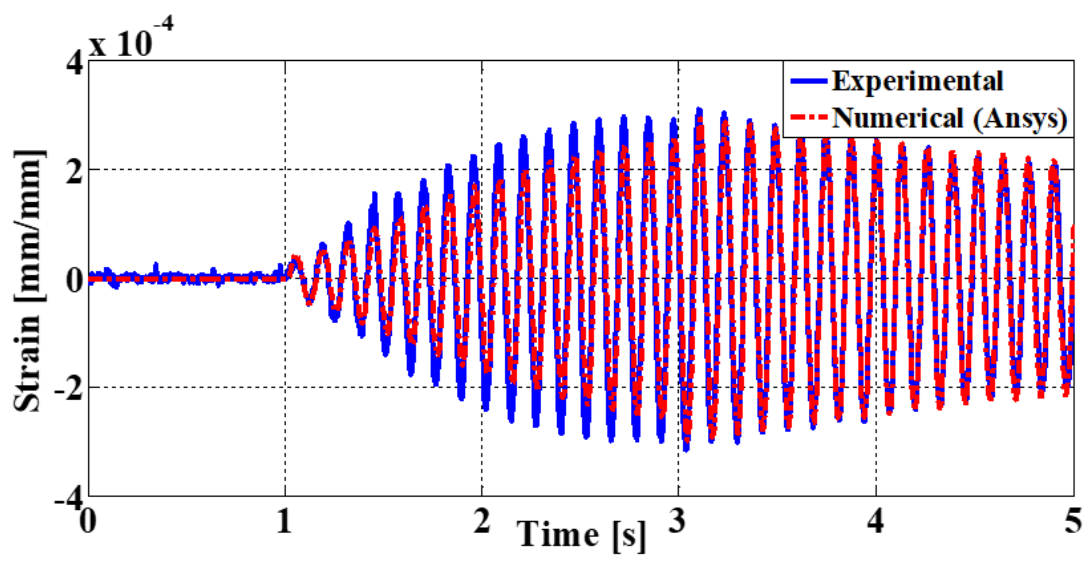

Fig. 3. The linear strain response by the piezoelectric patch excitation

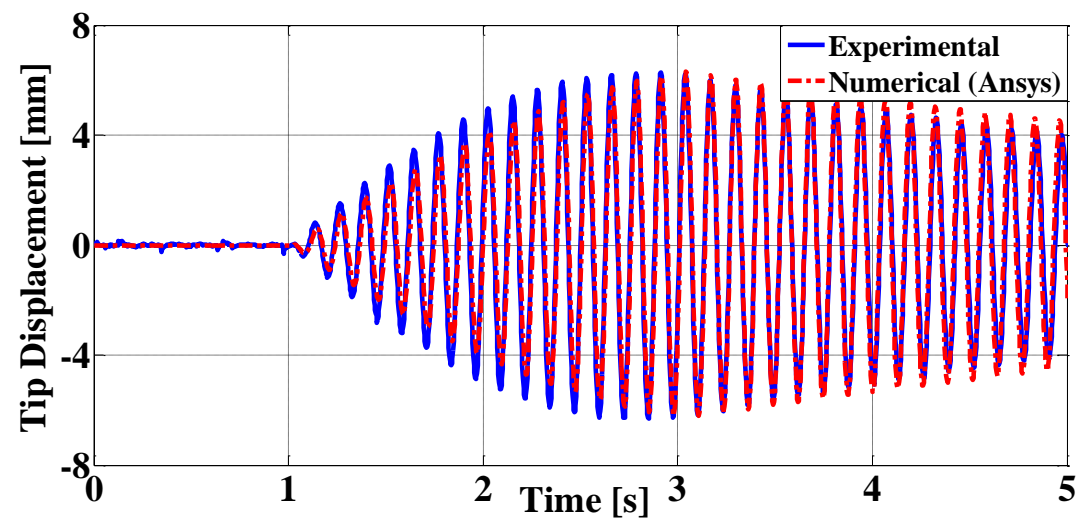

Fig. 4. The tip displacement response by the piezoelectric patch excitation 
Piezoelectric patch excitations initiate the model verification run of the smart beam. The system response also needs to be confirmed by the disturbance (shaker) excitation. For this purpose, the numerical and experimental models are excited by $+1 \mathrm{~N}$ shaker impulse signal for $0.1 \mathrm{~s}$ in both numerical simulations and experiments. A force sensor is used to measure and verify the amplitude in the experimental setup. The results are illustrated in Figs. 5 and 6. The linear strain and tip displacement responses are matched at a $90-95 \%$ rate in RMS for both results. The beginning region of the experimental and numerical values differ due to the prototype structure's hysteresis dynamical damping characteristics that are not inserted in the numerical analysis. Also, in Figs. 2-5, it has a lag of
1 second to show that the system was initially stable.

\section{Active vibration control of the designed smart beam}

The PPF controller generally provides better control performance in many modal controller studies. The researchers presented several versions of it in their work $[1,26]$. The PPF controller has different usages on several structures for active vibration control. A second-order transfer function (compensator) is used as positive feedback in the PPF method. Further details on the PPF method are referred $[9,24,27,28]$. The second-order transfer function of the PPF controller design is

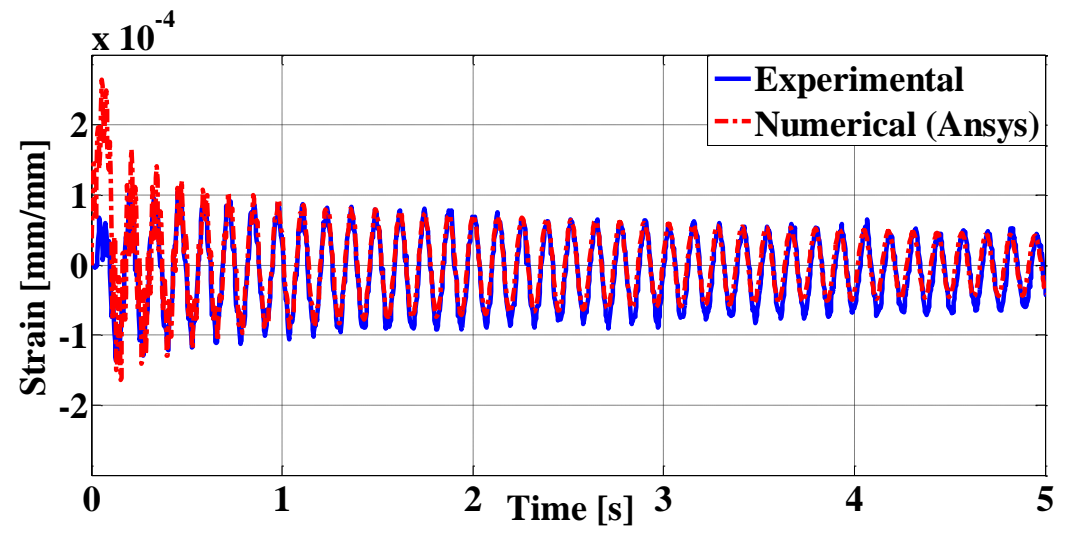

Fig. 5. The linear strain response by the shaker excitation

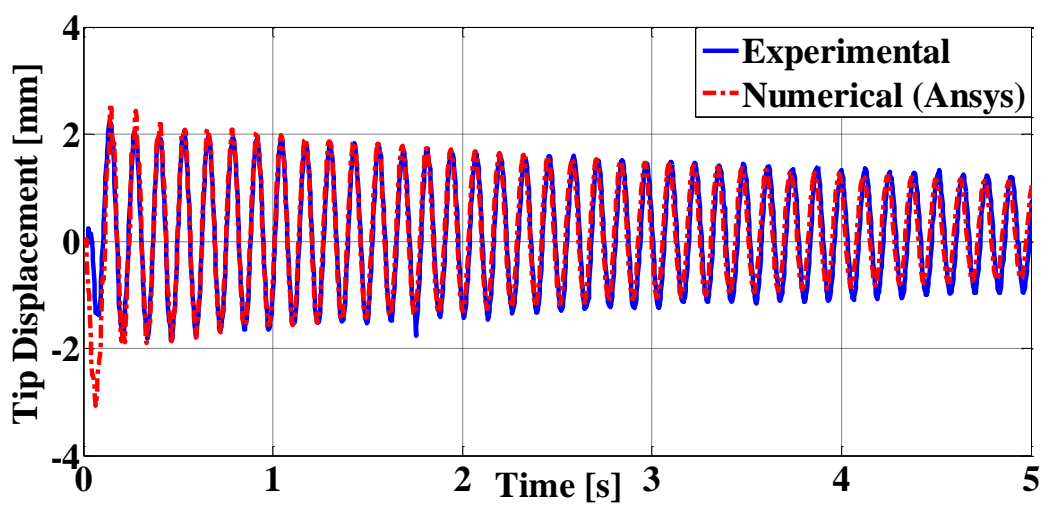

Fig. 6. The tip displacement response by the shaker excitation 
$H(s)_{n}=\frac{K}{s^{2}+2 \xi_{n} \omega_{n} s+\omega_{n}^{2}}$

where $K$ is a positive scalar gain and $\xi_{n}$ is the damping ratio of the $n$-th mode and $\omega_{n}$ is the natural frequency of the $n$-th mode. Here, the second-order compensators of the PPF controller are constituted to damp vibrations of the first three modes. A small damping ratio for the first three modes of the proposed beam is selected as 0.02 to show the free vibration controller performance. Also, the positive scalar gain is selected as $10^{7}$ due to practical considerations. Alternative design methodologies have been added to the PPF controller to improve the controller performance [14-16].

We propose a fuzzy-logic-based (FLB) observer to improve this work's positive position feedback (PPF) controller performance. The schematic representation of the PPF and FLBPPF controller designs is shown in Fig. 7. The fuzzy-logic-based observer is fed into the system output in the control methodology for obtaining the proposed FLBPPF controller, and it is not an individual controller design itself. In the fuzzy-logic-based method, the trained data obtained from the input and output values of the PPF controlled system are added to the system's output as positive forward-feeding. In this way, this observer helps to improve controller performance with fuzzy information about PPF controller behavior. It is observed that the PPF controller's overall performance is enhanced with an FLB contribution to the free vibration control.

The fuzzy-logic-based observer model is composed of a single input/output (SISO) system. The input signal, which is given in voltages, is formed as the fuzzy structure. On the other hand, the output signal, namely linear strain, is formatted to indicate a linear increase. The fuzzy membership functions used in the model are shown in Fig. 8, where NB, NS, PS, PB, and PVB are called negative big, negative small, positive small, positive big, and positive very big, respectively.

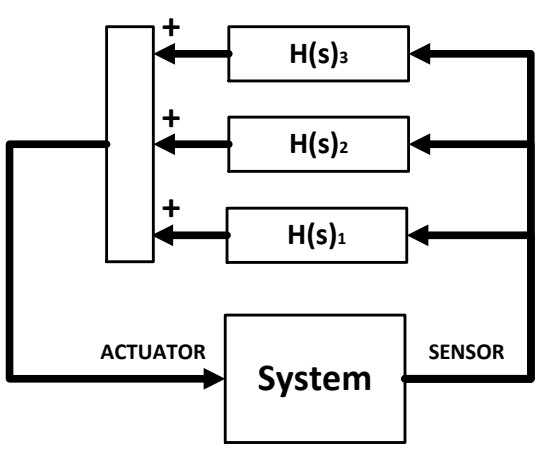

(a)

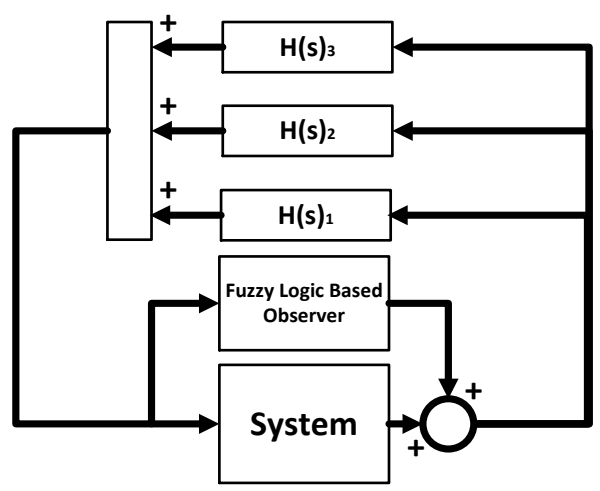

(b)

Fig. 7. The schematic representation of PPF (a) and FLBPPF (b) controller designs

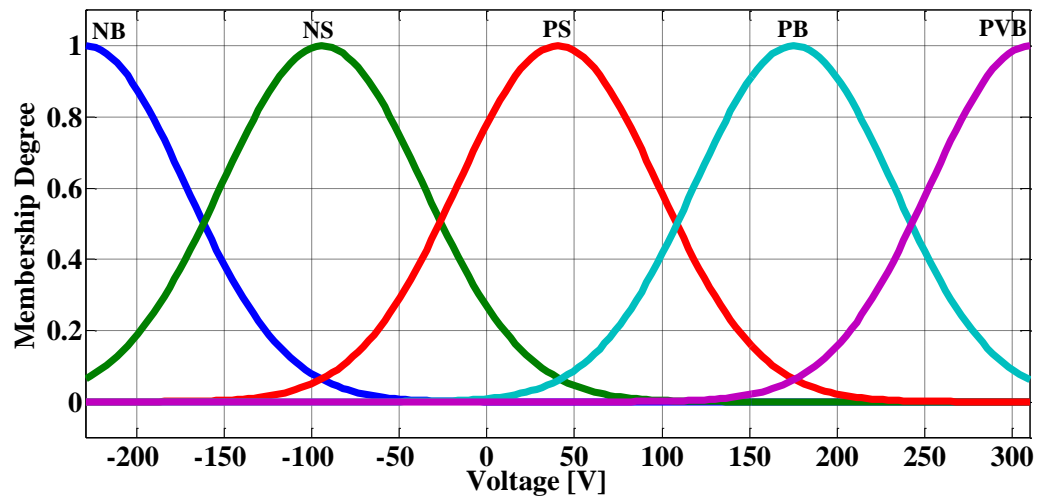

Fig. 8. Membership functions of the fuzzy logic model 
Table 1. Fuzzy logic rules

\begin{tabular}{cc}
\hline $\begin{array}{c}\text { Input } \\
\text { Voltage }[\mathrm{V}]\end{array}$ & $\begin{array}{c}\text { Output } \\
\text { Linear Strain }\end{array}$ \\
\hline NB & NB \\
NS & NS \\
PS & PS \\
PB & PB \\
PVB & PVB \\
\hline
\end{tabular}

In the study, Gauss-type membership functions are selected. The membership function's distribution range is specified by the fuzzy neural network in the model's contents. Thus, membership functions are distributed according to the neural network training results between -250 and $300 \mathrm{~V}$. The fuzzy logic model is composed of only five rules given in Table 1 .

The PPF and the FLBPPF controllers are designed for active vibration control in
MATLAB/Simulink. The simulation block diagram containing the FLBPPF controller is shown in Fig. 9. Due to the collocated FLBPPF controller design, the linear strain output is evaluated as positive position feedback instead of the tip displacement. For a better control performance, the coefficients are obtained by trial-error iterations and tests: $K_{1}=8$, $K_{2}=40, K_{3}=120, K_{4}=10$, and $K_{5}=0.5$ are selected.

\section{Results and discussions}

In this study, a beam's active free vibration control performance using a piezoelectric actuator is investigated by a PPF controller enhanced using an FLB observer. It is shown that the overall performance of the PPF controller is improved using a fuzzy-logic-based observer for the free vibration control. The time responses of the linear strain and tip displacement for both PPF controlled (experimental and numerical) and uncontrolled systems are presented in Fig. 10.

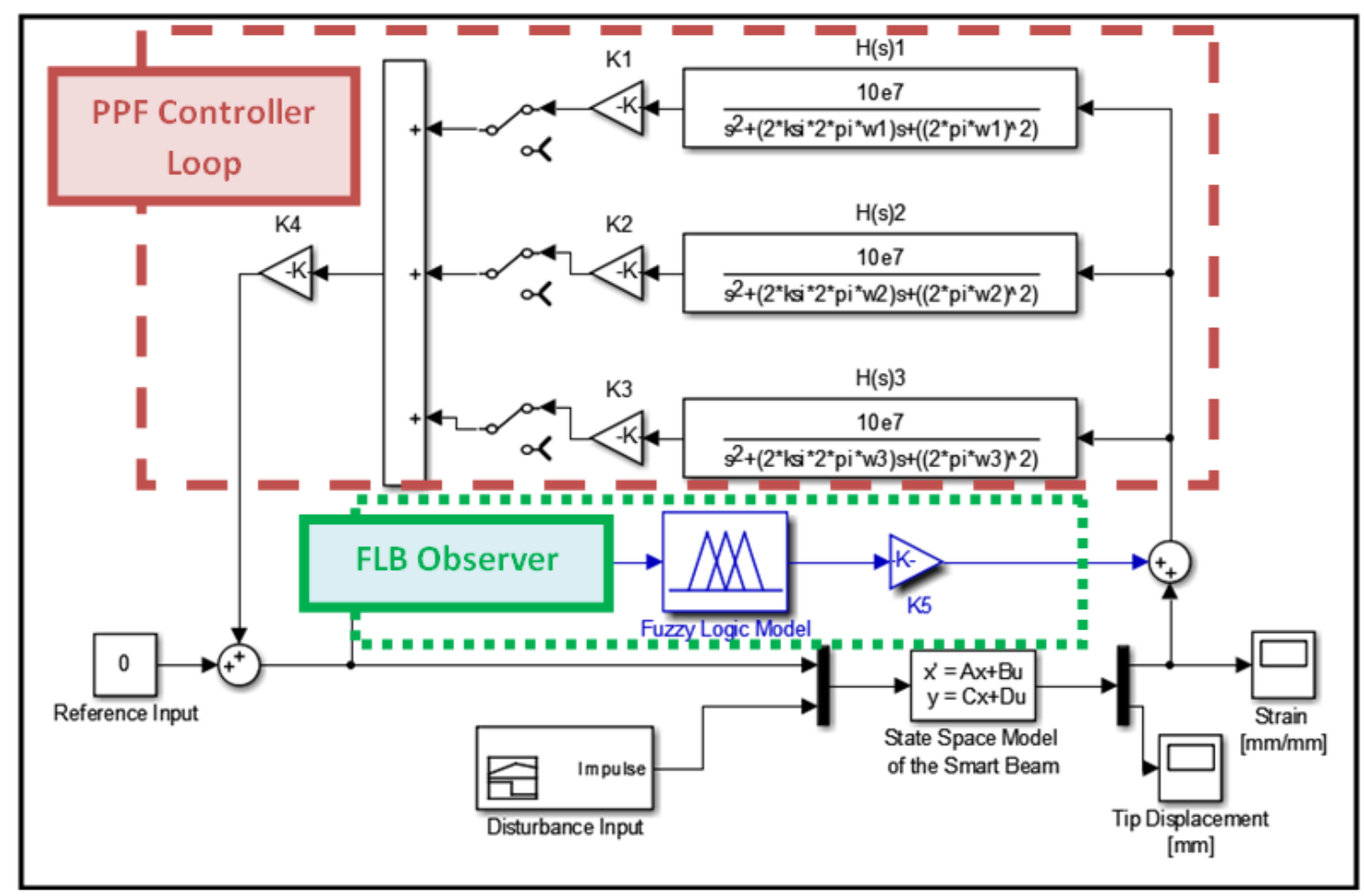

Fig. 9. The closed-loop FLBPPF control block diagram 


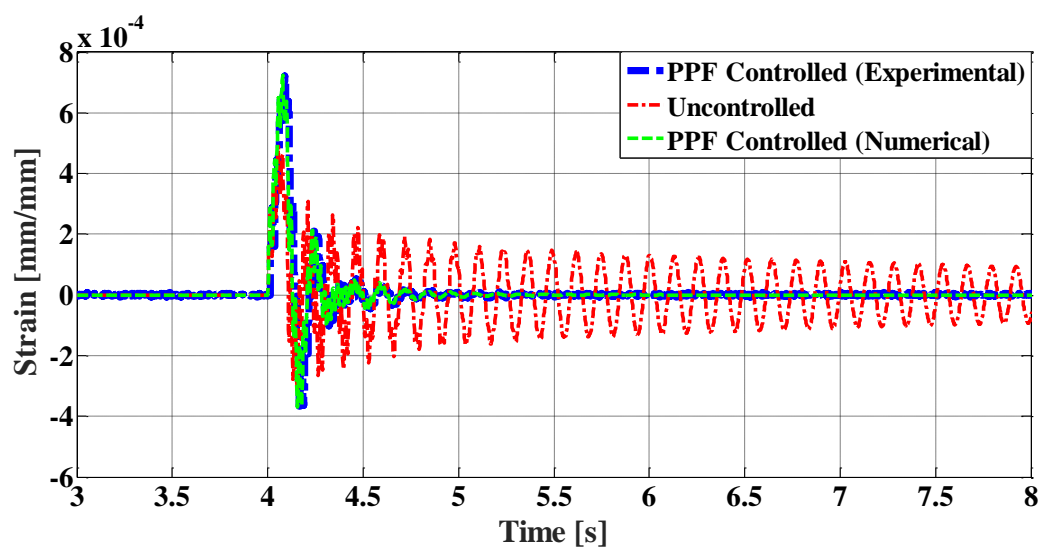

(a)

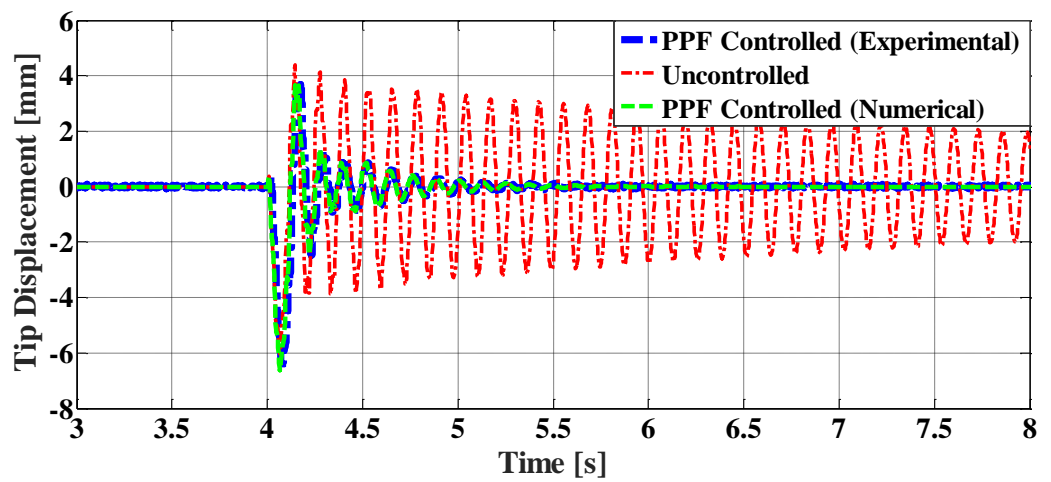

(b)

Fig. 10. The response of linear strain (a) and the response of tip displacement (b) of the PPF controlled and the uncontrolled system both numerically and experimentally

Experimental and numerical results are in agreement according to the PPF controlled without the fuzzy-logic-based observer. The PPF controller decreases the settling time of both linear strain and tip displacement from 20 seconds to 1.45 seconds and from 20 seconds to 1.8 seconds. Upon inspecting Fig. 10, the PPF controller design provides good performance for free vibration considering the beam's size and dynamic characteristics.

The comparison of both controller responses in simulations is illustrated in Fig. 11. Here, the free response of the FLBPPF controller is evaluated; the proposed controller reduces the settling times of both strain and tip displacement from 20 seconds to 1.15 seconds and from 20 seconds to 1.05 seconds, respectively. Also, it is observed that the control response of the FLBPPF is more effective than the PPF control response in terms of the linear strain and displacement.
The numerical settling time values of the PPF and FLBPPF controlled systems are tabulated in Table 2. According to Table 2, it is noted that active free vibration control of the system using PPF and FLBPPF control is realized successfully in both control techniques. However, the FLBPPF controller shows better damping performance in the simulation runs and experimental results according to the free vibration responses. Using the FLBPPF controller, the settling times of controlled systems are decreased by about $20.7 \%$ and $41.6 \%$ regarding the linear strain and tip displacement response concerning the PPF controller. It is shown that the tip settling time for the displacement response of the smart cantilever beam is significantly reduced. The reduction of tip displacement vibration is essential to reducing the beam root vibration according to the structural behavior. 


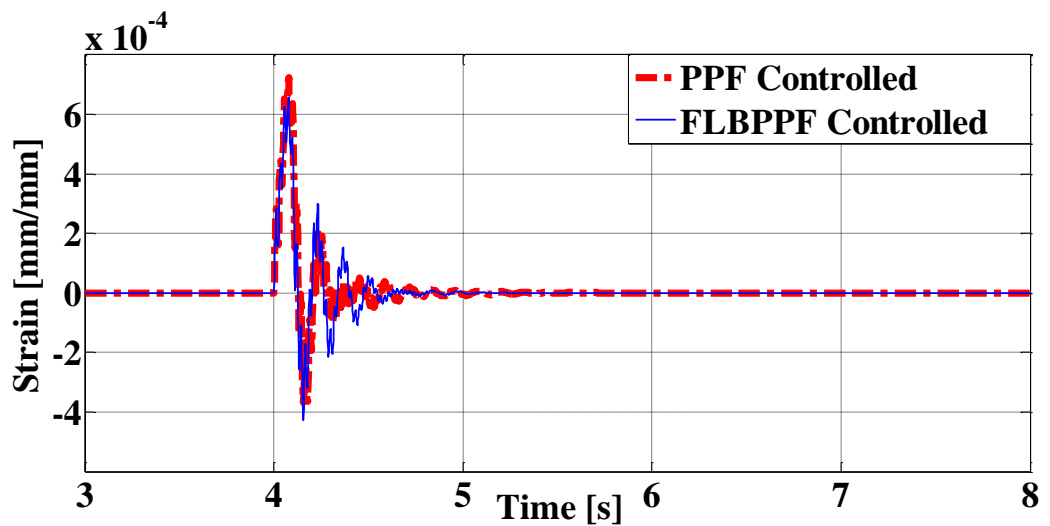

(a)

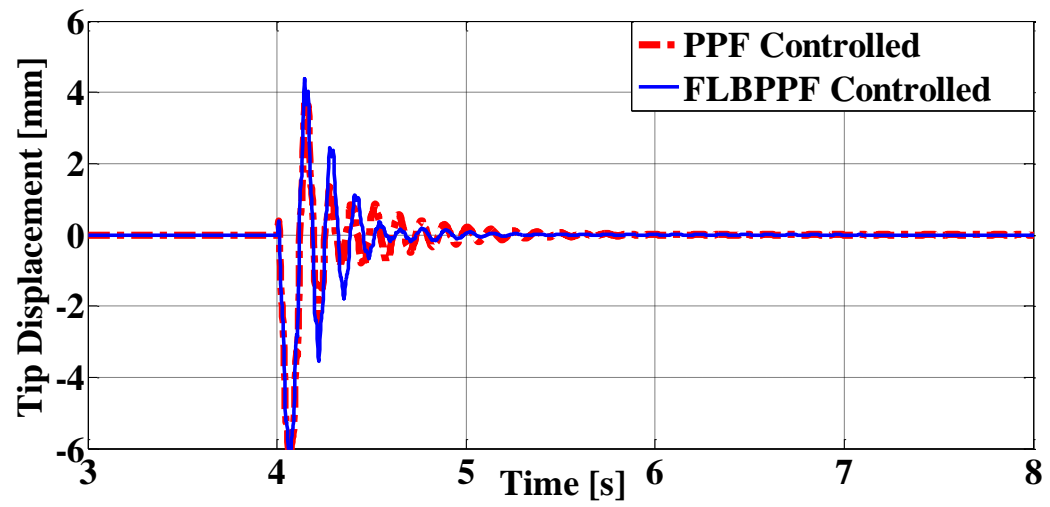

(b)

Fig. 11. The response of linear strain (a) and the response of tip displacement (b) of the PPF controlled and the FLBPPF controlled in the simulation

Table 2. The comparison of controller performances

\begin{tabular}{lccc}
\hline & Settling time [s] & $\begin{array}{c}\text { Relative } \\
\text { improvement } \\
\text { of FLBPPF [\%] }\end{array}$ \\
\hline Linear Strain & 1.45 & 1.15 & 20.7 \\
Tip Displacement & 1.80 & 1.05 & 41.6 \\
\hline
\end{tabular}

\section{Conclusion}

A fuzzy-logic-based observer is designed to improve the positive position feedback (PPF) controller performance for the flexible smart beam's active free vibration control. The experimental applications are performed according to the modeling and controller design. In this study, uncontrolled, PPF, and FLBPPF controlled transient responses are investigated and compared in linear strain and tip displacement values, both numerically and experimentally. The numerical and experimental results indicate that the FLBPPF controller performs superior to the PPF controller response. Thus, this study's main contribution is that the FLB observer improves the PPF controller's performance for free vibration control.

\section{Declaration of conflicting interests}

The author(s) declared no potential conflicts of interest with respect to the research, authorship, and/or publication of this article.

\section{References}

[1] Omidi E, Mahmoodi SN, Shepard WS (2016) Multi positive feedback control method for active vibration suppression in flexible structures. Mechatronics 33:23-33.

[2] Boz U, Aridogan U, Basdogan I (2015) A numerical and experimental study of optimal velocity feedback control for vibration suppression 
of a plate-like structure. Journal of Low Frequency Noise, Vibration and Active Control, 34:343-359.

[3] Liu C, Yue S, Zhou J (2016) Piezoelectric optimal delayed feedback control for nonlinear vibration of beams. Journal of Low Frequency Noise, Vibration and Active Control 35:25-38.

[4] Zhang S, Schmidt R, Qin X (2015) Active vibration control of piezoelectric bonded smart structures using PID algorithm. Chinese Journal of Aeronautics 28:305-313.

[5] Wang E, Zhang J, He L (2010) Active vibration control of piezoelectric intelligent structures. Journal of Computers 5(3):410-419.

[6] Bendine K, Boukhoulda FB, Haddag B, Nouari M (2019) Active vibration control of composite plate with optimal placement of piezoelectric patches. Mechanics of Advanced Materials and Structures 26(4):341-349.

[7] Biglar M, Gromada M, Stachowicz F, Trzepieciński T (2015) Optimal configuration of piezoelectric sensors and actuators for active vibration control of a plate using a genetic algorithm. Acta Mechanica 226:3451-3462.

[8] Chhabra D, Bhushan G, Chandna P (2015) Optimal placement of piezoelectric actuators on plate structures for active vibration control via modified control matrix and singular value decomposition approach using modified heuristic genetic algorithm. Mechanics of Advanced Materials and Structures 23:272-280.

[9] Lüleci F (2013) Active vibration control of beam and plates by using piezoelectric patch actuators. MSc Thesis, Middle East Technical University, Ankara.

[10] Wang RL, Gu H, Song G (2014) Adaptive robust sliding mode vibration control of a flexible beam using piezoceramic sensor and actuator: An experimental study. Mathematical Problems in Engineering 2014:606817.

[11] Zhang H, Wang R, Wang J, Shi Y (2014) Robust finite frequency static-output-feedback control with application to vibration active control of structural systems. Mechatronics 24:354-366.

[12] Parameswaran AP, Ananthakrishnan B, Gangadharan KV (2015) Design and development of a model free robust controller for active control of dominant flexural modes of vibrations in a smart system. Journal of Sound and Vibration 355:1-18.

[13] Nestorović T, Oveisi A (2015) Robust controller for the vibration suppression of an active piezoelectric beam. $7^{\text {th }}$ ECCOMAS Thematic
Conference on Smart Structures and Materials, Ponta Delgada, Azores, Portugal.

[14] Kwak MK, Heo S (2007) Active vibration control of smart grid structure by multi-input and multioutput positive position feedback controller. Journal of Sound and Vibration 304:230-245.

[15] Orszulik R, Shan J (2011) Multi-mode adaptive positive position feedback: An experimental study, In: American Control Conference (ACC), IEEE, pp. 3315-3319.

[16] Ferrari G, Amabili M (2015), Active vibration control of a sandwich plate by non-collocated positive position feedback. Journal of Sound and Vibration 342:44-56.

[17] Zorić ND, Simonović AM, Mitrović ZS, Stupar SN, Obradović AM, Lukić NS (2014) Free vibration control of smart composite beams using particle swarm optimized self-tuning fuzzy logic controller. Journal of Sound and Vibration 333:5244-5268.

[18] Tairidis G, Foutsitzi G, Koutsianitis P, Stavroulakis GE (2016) Fine tuning of a fuzzy controller for vibration suppression of smart plates using genetic algorithms. Advances in Engineering Software 101:123-135.

[19] Bendine K, Boukhoulda BF, Nouari M, Satla Z (2017) Structural modeling and active vibration control of smart FGM plate through ANSYS. International Journal of Computational Methods 14(04):1750042.

[20] Maruani J, Bruant I, Pablo F, Gallimard L (2017) A numerical efficiency study on the active vibration control for a FGPM beam. Composite Structures 182:478-486.

[21] Tian J, Guo Q, Shi G (2020) Laminated piezoelectric beam element for dynamic analysis of piezo-laminated smart beams and GA-based LQR active vibration control. Composite Structures 252:112480.

[22] Williams D, Haddad Khodaparast H, Jiffri S, Yang C (2019) Active vibration control using piezoelectric actuators employing practical components. Journal of Vibration and Control 25:2784-2798.

[23] Xie C, Wu Y, Liu Z (2018) Modeling and active vibration control of lattice grid beam with piezoelectric fiber composite using fractional order $\mathrm{PD} \mu$ algorithm. Composite Structures 198:126134.

[24] Gülbahçe E, Çelik M (2018) Active vibration control of a smart beam by a tuner-based PID 
controller. Journal of Low Frequency Noise, Vibration and Active Control 37:1125-1133.

[25] Khot SM, Yelve NP (2010) Modeling and response analysis of dynamic systems by using ANSYSC and MATLABC. Journal of Vibration and Control 17:953-958.

[26] Fenik Š, Starek L (2008) Optimal PPF controller for multimodal vibration suppression. Engineering Mechanics 15:153-173
[27] Fanson J, Caughey TK (1990) Positive position feedback control for large space structures. AIAA Journal 28:717-724.

[28] Omidi E, Mahmoodi N (2015) Hybrid positive feedback control for active vibration attenuation of flexible structures. IEEE/ASME Transactions on Mechatronics 20:1790-1797. 